\title{
High efficacy of BGD (bendamustine, gemcitabine, and dexamethasone) in relapsed/refractory Hodgkin Lymphoma
}

\author{
Ryszard Swoboda ${ }^{1} \cdot$ Sebastian Giebel ${ }^{1} \cdot$ Wanda Knopińska-Posłuszny ${ }^{2} \cdot$ Ewa Chmielowska $^{3,4}$ - Joanna Drozd- \\ Sokołowska ${ }^{5}$ - Ewa Paszkiewicz-Kozik ${ }^{6}$ - Waldemar Kulikowski ${ }^{7}$ - Michał Taszner ${ }^{8}$ - Włodzimierz Mendrek ${ }^{1}$. \\ Jacek Najda ${ }^{1}$. Tomasz Czerw ${ }^{1}$. Magdalena Olszewska-Szopa ${ }^{8}$. Anna Czyż ${ }^{9}$. Agnieszka Giza ${ }^{10}$. \\ Wojciech Spychałowicz ${ }^{11}$. Edyta Subocz ${ }^{12}$. Paweł Szwedyk ${ }^{13} \cdot$ Aleksandra Krzywon $^{14} \cdot$ Agata Wilk $^{14}$. \\ Jan Maciej Zaucha ${ }^{8}$ (B)
}

Received: 30 May 2020 / Accepted: 2 February 2021 / Published online: 24 February 2021

(C) The Author(s) 2021

\begin{abstract}
The optimal salvage therapy in relapsed/refractory Hodgkin lymphoma (R/R HL) has not been defined so far. The goal of this multicenter retrospective study was to evaluate efficacy and safety of BGD (bendamustine, gemcitabine, dexamethasone) as a second or subsequent line of therapy in classical R/R HL. We have evaluated 92 consecutive R/R HL patients treated with BGD. Median age was 34.5 (19-82) years. Fifty-eight patients (63\%) had received 2 or more lines of chemotherapy, 32 patients (34.8\%) radiotherapy, and 21 patients (22.8\%) an autologous hematopoietic stem cell transplantation (autoHCT). Forty-four patients (47.8\%) were resistant to first line of chemotherapy. BGD therapy consisted of bendamustine $90 \mathrm{mg} / \mathrm{m}^{2}$ on days 1 and 2 , gemcitabine $800 \mathrm{mg} / \mathrm{m}^{2}$ on days 1 and 4, dexamethasone $40 \mathrm{mg}$ on days $1-4$. Median number of BGD cycles was 4 (2-7). The following adverse events $\geq 3$ grade were noted: neutropenia (22.8\%), thrombocytopenia (20.7\%), anemia (15.2\%), infections (10.9\%), AST/ALT increase (2.2\%), and skin rush (1.1\%). After BGD therapy, 51 (55.4\%) patients achieved complete remission, $23(25 \%)$ - partial response, 7 (7.6\%)-stable disease, and 11 (12\%) patients experienced progression disease. AutoHCT was conducted in 42 (45.7\%) patients after BGD therapy, and allogeneic HCT (alloHCT) in 16 (17.4\%) patients. Median progressionfree survival was 21 months. BGD is a highly effective, well-tolerated salvage regimen for patients with R/R HL, providing an excellent bridge to auto- or alloHCT.
\end{abstract}

Wojciech Spychałowicz passed away during the writing of this article.

Jan Maciej Zaucha

jzaucha@gumed.edu.pl

1 Department of Bone Marrow Transplantation and Oncohematology, Maria Sklodowska-Curie National Research Institute of Oncology, Gliwice branch, Gliwice, Poland

2 Department of Hematology and Bone Marrow Transplantation, Pomeranian Hospitals, Gdynia, Poland

3 Oncologic Hospital, Tomaszów Mazowiecki, Poland

4 Department of Oncology, Oncology Centre, Bydgoszcz, Poland

5 Department of Hematology, Oncology and Internal Diseases, Medical University of Warsaw, Warsaw, Poland

6 Department of Lymphoid Malignancies, Maria Sklodowska-Curie National Research Institute of Oncology, Warsaw branch, Warsaw, Poland

7 Department of Hematology, Independent Public Health Care Ministry of the Interior of Warmia and Mazury Oncology Center, Olsztyn, Poland
8 Department of Hematology and Transplantology, Medical University of Gdańsk, Gdańsk, Poland

9 Department of Hematology, Blood Neoplasms and Bone Marrow Transplantation, Wrocław Medical University, Wrocław, Poland

10

Department of Hematology, Jagiellonian University, Krakow, Poland

11 Internal Medicine and Oncology Clinic, Silesian Medical University, Katowice, Poland

12 Department of Hematology, Military Institute of Medicine, Warsaw, Poland

13 Department of Hematology, Ludwik Rydygier Hospital, Krakow, Poland

14 Department of Biostatistics and Bioinformatics, Maria Sklodowska-Curie National Research Institute of Oncology, Gliwice Branch, Gliwice, Poland 
Keywords Hodgkin lymphoma $\cdot$ Chemotherapy $\cdot$ Treatment $\cdot$ Salvage

\section{Introduction}

Hodgkin lymphoma (HL), accounting for approximately $10 \%$ of all lymphomas, is one of the most curable malignancies. However, up to $30 \%$ of patients do not respond to the first-line therapy or relapse after initial response [1]. For patients with relapsed or refractory disease, salvage chemotherapy followed by high-dose chemotherapy with autologous hematopoietic stem cell transplantation (autoHCT) is still the treatment of choice $[2,3]$. The long-term cure can be obtained in up to $80 \%$ of patients provided a complete metabolic remission (CMR) is achieved before transplant [4]. Consequently, the optimal salvage regimen should be highly effective but also should have a high mobilization rate. However, the standard for salvage chemotherapy before autoHCT is still not established. The most commonly used are platinum-based ICE (ifosfamide, carboplatin, etoposide); DHAP (dexamethasone, cytarabine, cisplatin); ESHAP (etoposide, methylprednisolone, cytarabine, cisplatin); and gemcitabine-based GDP (gemcitabine, dexamethasone, cisplatin), GVD (gemcitabine, vinorelbine, liposomal doxorubicin), IGEV (ifosfamide, gemcitabine, vinorelbine), and GCD (gemcitabine, carboplatin, dexamethasone) combination chemotherapy with response rates ranging between 54 and $88 \%$ and mobilization rate of $86-100 \%$ [5-10]. Due to rather low rate of complete responses (CRs) achieved with the most frequently used salvage regimens, there is the persisting need to develop new salvage regimens especially in the second-line treatment. Recently, bendamustine both in monotherapy and in combination with other drugs was shown to induce high response rates with an acceptable toxicity profile in third or more line in patients with relapsed/refractory (R/R) HL [11-13]. Experience with bendamustine in the second line is very limited. Santoro et al. modified their original IGEV protocol substituting ifosfamide with bendamustine achieving a very high efficacy as a second-line therapy in patients with R/R HL $[9,14]$. The Polish Lymphoma Research Group (PLRG) proposed replacement of vinorelbine with dexamethasone (bendamustine, gemcitabine, dexamethasone; BGD regimen) and is carrying out a prospective, multicenter study in patients with progressive disease during or after ABVD treatment [15] based on the very good preliminary results obtained with $\mathrm{BGD}$ in heavily pretreated $\mathrm{R} / \mathrm{R} \mathrm{HL}$ patients [16]. Here we report long-term outcome of these patients enrolled to the multicenter retrospective PLRG study aiming at evaluating the efficacy and toxicity of BGD in a real-life setting.

\section{Methods}

\section{Study design}

We retrospectively reviewed the data of all patients aged $\geq 18$ years with $\mathrm{R} / \mathrm{R}$ HL who were treated with $\mathrm{BGD}$ regimen between April 2012 and December 2018 in 15 centers allied within the PLRG. Primary refractory HL was defined as no CMR achieved after the first line or if progression occurred within 3 months after completion of the first-line chemotherapy. In patients with relapsed HL, the disease reappeared later after achieving CMR. Patients' records were reviewed to obtain patient characteristics at diagnosis and the start of BGD treatment, including clinical stage according to the Lugano system, presence of B symptoms, extranodal site involvement, and bulky disease.

\section{Treatment and response criteria}

The dosage and administration schedule of BGD is shown in Table 1. The interim imaging assessment was performed after second or third cycle of BGD in 86 patients (93.5\%). Patients could continue BGD treatment up to 4 cycles or longer at the discretion of a treating physician. The metabolic response to BGD treatment at the end of the therapy was assessed according to the Lugano treatment response criteria using 18F-fluorodeoxyglucose (18F-FDG) positron emission tomography/computed tomography (PET/CT) [17]. The 18F-FDG uptake less than in the liver was defined as CMR. The higher 18F-FDG uptake, but decreased from baseline, was defined as partial metabolic response (PMR). In case of no significant change in $18 \mathrm{~F}-\mathrm{FDG}$ uptake from baseline or new FDG-avid foci, stable or progressive disease (SD or PD) were diagnosed, respectively. The overall response rate (ORR) was defined as the sum of CMR and PMR.

\section{Study end-points and statistical analysis}

Primary end-point was the percentage of CMR and ORR whereas progression-free survival (PFS) and overall survival (OS) as well as adverse events (AEs) were secondary end-points. PFS was defined as the time from start of BGD treatment to the date of documented disease progression, death from any cause, or start of new anticancer therapy. The patients at the time of autoHCT or allogeneic hematopoietic stem cell transplantation (alloHCT) were censored for PFS since transplants were not considered a 
Table 1 BGD regimen repeated every 4 weeks

\begin{tabular}{llll}
\hline Drug & Dose & Route of administration & Day of administration \\
\hline Bendamustine & $90 \mathrm{mg} / \mathrm{m}^{2}$ & i.v. $60 \mathrm{~min}$ & 1 and 2 \\
Gemcitabine & $800 \mathrm{mg} / \mathrm{m}^{2}$ & i.v. $30 \mathrm{~min}$ & 1 and 4 \\
Dexamethasone & $40 \mathrm{mg}$ & i.v. or p.o. & $1,2,3$, and 4 \\
\hline
\end{tabular}

${ }^{\mathrm{a}}$ i.v., intravenous; p.o., per os
Table 2 Demographics and clinical characteristics of 92 subjects

\begin{tabular}{|c|c|c|}
\hline Characteristic & No. & $\%$ \\
\hline \multicolumn{3}{|l|}{ Age, years } \\
\hline - Median (range) & \multicolumn{2}{|l|}{$34.5(19-82)$} \\
\hline$-\geq 60$ years & 9 & 9.7 \\
\hline \multicolumn{3}{|l|}{ Sex } \\
\hline - Male & 44 & 47.8 \\
\hline - Female & 48 & 52.2 \\
\hline \multicolumn{3}{|c|}{ Lugano classification at diagnosis/before BGD ${ }^{\mathrm{a}}$} \\
\hline$-I$ & $0 / 3$ & $0 / 3.3$ \\
\hline- II & $33 / 38$ & $35.9 / 41.3$ \\
\hline - III & $25 / 9$ & $27.2 / 9.8$ \\
\hline$-\mathrm{IV}$ & $34 / 42$ & $37 / 45.7$ \\
\hline B-symptoms at diagnosis/before BGD ${ }^{\mathrm{a}}$ & $67 / 27$ & $72.9 / 29.3$ \\
\hline $\begin{array}{l}\text { Extranodal site involvement } \\
\text { at diagnosis/before BGD }\end{array}$ & $32 / 39$ & $34.8 / 42.4$ \\
\hline Bulky disease at diagnosis/before BGD ${ }^{\mathrm{a}}$ & $32 / 10$ & $34.8 / 10.9$ \\
\hline \multicolumn{3}{|l|}{ First-line treatment } \\
\hline $\mathrm{ABVD}^{\mathrm{b}}$ & 74 & 80.4 \\
\hline $\mathrm{BEACOPP}^{\mathrm{c}}$ & 13 & 14.1 \\
\hline Other $^{\mathrm{d}}$ & 5 & 5.4 \\
\hline \multicolumn{3}{|l|}{ No. of previous treatment lines } \\
\hline-1. & 34 & 37 \\
\hline-2 & 26 & 28.3 \\
\hline-3. & 16 & 17.4 \\
\hline-4. & 9 & 9.8 \\
\hline-5 & 3 & 3.3 \\
\hline-6 & 4 & 4.3 \\
\hline Primary refractory to 1 st-line treatment & 44 & 47.8 \\
\hline Patents with late (> 12 months) relapse & 20 & 21.7 \\
\hline \multicolumn{3}{|l|}{ No. of $\mathrm{BGD}^{\mathrm{a}}$ courses } \\
\hline - Median (range) & $4(2-7)$ & \\
\hline Radiotherapy prior to $\mathrm{BGD}^{\mathrm{a}}$ & 32 & 34.8 \\
\hline Prior autoHCT $\mathrm{T}^{\mathrm{e}}$ & 21 & 22.8 \\
\hline Prior alloHCT ${ }^{\mathrm{f}}$ & 3 & 3.3 \\
\hline
\end{tabular}

${ }^{\mathrm{a}} B G D$, bendamustine, gemcitabine, dexamethasone

${ }^{\mathrm{b}} A B V D$, adriamycin, bleomycin, vinblastine, dacarbazine

${ }^{\mathrm{c}} B E A C O P P$, bleomycin, cyclophosphamide, doxorubicin, etoposide, prednisone, procarbazine, vincristine

${ }^{\mathrm{d}}$ Other: $P V A G$, prednisone, vincristine, adriamycin, gemcitabine; $O E P A /$ COPDAC, vincristine, etoposide, prednisone, doxorubicin/ cyclophosphamide, vincristine, prednisone, dacarbazine

e autoHCT, autologous hematopoietic cell transplantation

f alloHCT, allogeneic hematopoietic cell transplantation new anticancer therapy. OS was defined as the time from the first BGD administration to death for any reason. AEs were evaluated using Common Terminology Criteria for Adverse Events (CTCAE), version 4.0 [18]. PFS and OS were estimated using the Kaplan-Meier method. Ninetyfive percent confidence intervals (CIs) for the survival curves were calculated for chosen times. The log-rank test was performed to compare survival curves between groups. Two-sided $P$ values $\leq 0.05$ were considered statistically

Table 3 Response to BGD therapy

\begin{tabular}{|c|c|c|}
\hline & No. & $\%(95 \% \mathrm{CI})$ \\
\hline Interim (after $2-3$ courses) & $n=86$ & \\
\hline$-\mathrm{PMD}^{\mathrm{a}}$ & 6 & $7(1.6-12.4)$ \\
\hline$-\mathrm{SMD}^{\mathrm{b}}$ & 13 & $15.1(7.5-22.7)$ \\
\hline$-\mathrm{PMR}^{\mathrm{c}}$ & 34 & $39.5(29.2-49.9)$ \\
\hline$-\mathrm{CMR}^{\mathrm{d}}$ & 33 & $38.4(28.1-48.6)$ \\
\hline- ORR $^{\mathrm{e}}$ & 67 & $77.9(69.1-86.7)$ \\
\hline End of BGD ${ }^{f}$ therapy & $n=92$ & \\
\hline$-\mathrm{PMD}^{\mathrm{a}}$ & 11 & $12(5.3-18.6)$ \\
\hline$-\mathrm{SMD}^{\mathrm{b}}$ & 7 & $7.6(2.2-13.0)$ \\
\hline$-\mathrm{PMR}^{\mathrm{c}}$ & 23 & $25(16.2-33.8)$ \\
\hline$-\mathrm{CMR}^{\mathrm{d}}$ & 51 & $55.4(45.3-65.6)$ \\
\hline$-\mathrm{ORR}^{\mathrm{e}}$ & 74 & $80.4(2.3-88.5)$ \\
\hline \multicolumn{3}{|c|}{ AutoHCT ${ }^{\mathrm{g}}$ after BGD therapy } \\
\hline - Yes & 42 & 45.7 \\
\hline - No & 50 & 54.3 \\
\hline \multicolumn{3}{|l|}{ AlloHCT ${ }^{\mathrm{h}}$ after BGD therapy } \\
\hline - Yes & 16 & 17.4 \\
\hline - No & 76 & 82.6 \\
\hline
\end{tabular}

${ }^{\text {a }} P M D$, progressive metabolic disease

${ }^{\mathrm{b}} S M D$, stable metabolic disease

${ }^{\mathrm{c}} P M R$, partial metabolic response

${ }^{\mathrm{d}} C M R$, complete metabolic response

${ }^{\mathrm{e}} \mathrm{ORR}$, overall response rate

${ }^{\mathrm{f}} B G D$, bendamustine, gemcitabine, dexamethasone

$\mathrm{g}$ autoHCT, autologous hematopoietic cell transplantation

${ }^{\mathrm{h}}$ alloHCT, allogeneic hematopoietic cell transplantation 
significant. The statistics were performed descriptively. Statistical analysis was performed using Statistica software (version 13.1, Tulsa, OK, USA) and R statistical software package version 4.0.1. (R Foundation for Statistical Computing, http://www.r-project.org).

\section{Results}

\section{Patients' characteristics}

The median age of 92 analyzed patients was 34.5 (range from 19 to 82 years) years with 9 patients at the age or above 60 years. More than $60 \%$ of patients were in advanced stages of HL at the time of diagnosis (III and IV according to the Lugano classification). Median number of prior chemotherapy lines was 2 (range from 1 to 6 lines). Thirty-four patients $(37 \%)$ had previously been treated with only one line of chemotherapy. ABVD was the first-line therapy in $80.4 \%$ cases. Forty-four patients $(47.8 \%)$ were primary refractory to the first-line chemotherapy. Almost $35 \%$ of patients had received radiotherapy prior to BGD treatment. Twenty-one patients $(22.8 \%)$ underwent autoHCT, and three patients $(3.3 \%)$ underwent alloHCT prior to BGD treatment. The median number of BGD cycles was 4 (range from 2 to 7 cycles). Demographic and clinical data are shown in Table 2.

\section{Efficacy of BGD}

Out of 86 patients who were assessed by interim PET/CT after 2 or 3 cycles of BGD, $67(77.9 \%)$ patients achieved overall response, including $33(38.4 \%)$ CMRs. At the end of BGD therapy, ORR and CMR rate increased to $80.4 \%$ and $55.4 \%$, respectively. Eleven patients $(12 \%)$ experienced disease progression, and seven patients $(7.6 \%)$ had stable disease.
Fig. 1 Progression-free survival (PFS) for the entire population

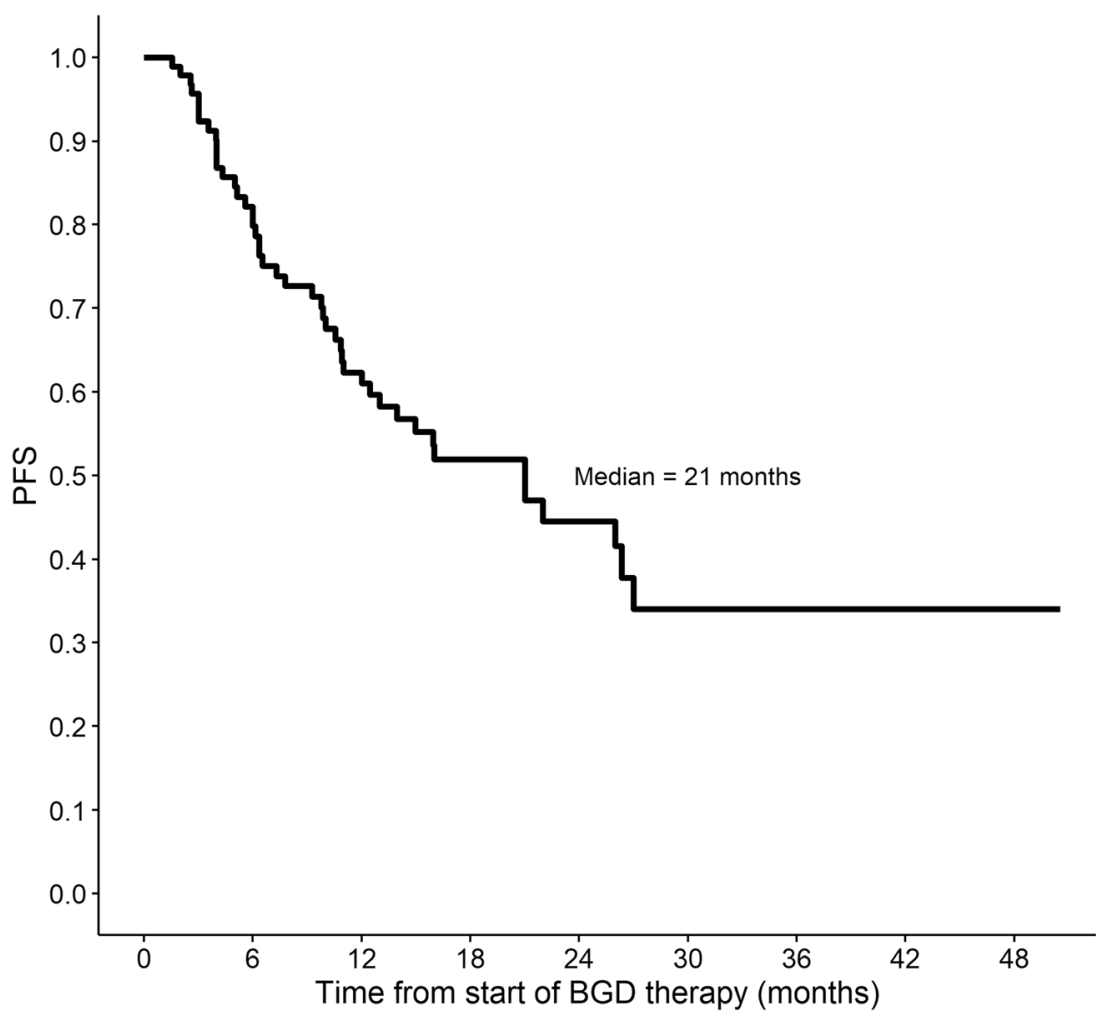

Number at risk

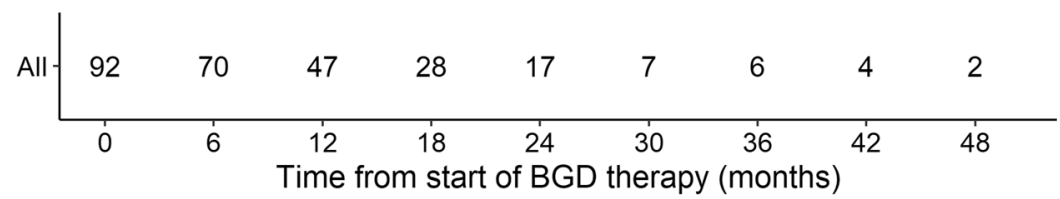


Fig. 2 Overall survival (OS) for the entire population

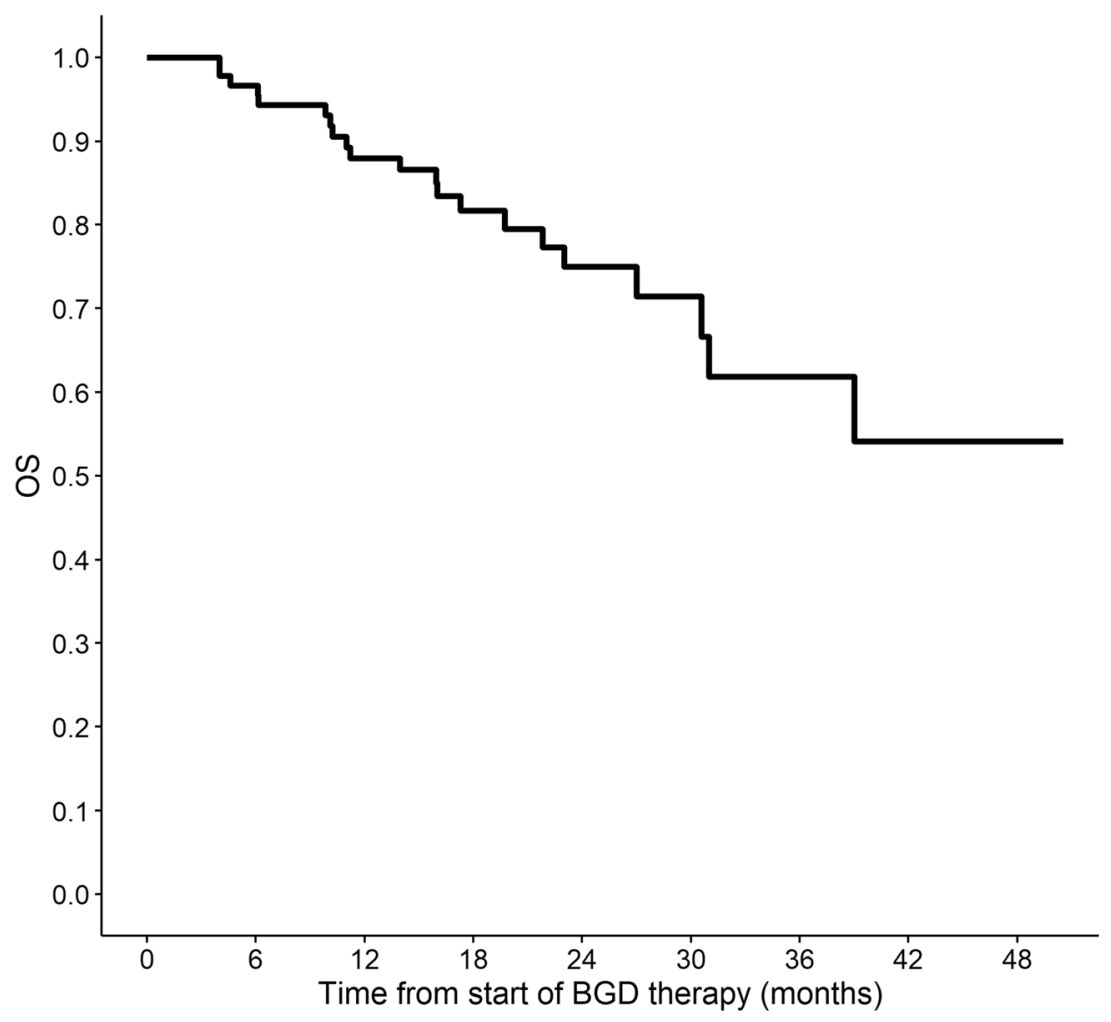

Number at risk

\begin{tabular}{|c|c|c|c|c|c|c|c|c|}
\hline 92 & 84 & 67 & 45 & 30 & 15 & 9 & 6 & 2 \\
\hline 0 & 6 & 12 & 18 & 24 & 30 & 36 & 42 & 48 \\
\hline
\end{tabular}

Among 34 patients who achieved PMR in the interim imaging test, $14(41.2 \%)$ patients achieved CMR at the end of BGD treatment. In the subgroup of patients treated with BGD only as a second line of chemotherapy $(n=34)$, ORR was $79.4 \%$ while CMR rate was $64.7 \%$. Out of 44 patients being refractory to the first line of chemotherapy, $30(68.2 \%)$ patients achieved overall response and $34.1 \%$ achieved CMR. Among the whole study population, five patients were refractory to BEACOPP given as the first line of chemotherapy. All these patients achieved response and two of them $(40 \%)$ achieved CMR after BGD. The autoHCT was successfully performed after BGD therapy in $42(45.7 \%)$ patients. Furthermore, $16(17.4 \%)$ patients underwent alloHCT after BGD therapy (Table 3). Among 21 patients treated with autoHCT before BGD therapy, 18 (85.7\%) achieved response, $11(52.4 \%) \mathrm{CMR}$, and 9 $(42.9 \%)$ patients proceeded to alloHCT. PFS and OS are shown as Kaplan-Meier curves in Figs. 1 and 2. With a median follow-up of 18 months (range from 3 to 51 months), the median PFS for the overall population was 21 months while the median OS was not reached. PFS and $\mathrm{OS}$ rates at 2 years were $44.5 \%$ (95\% CI: 33.7-58.8) and $75 \%$ (95\%CI: 64.8-86.7), respectively. There were no differences between patients with relapsed or primary refractory HL in terms of PFS and OS (Figs. 3 and $4, P>$ 0.05). Similarly, no statistical differences in PFS and OS were noted between patients in whom BGD was used after first line or subsequent line of chemotherapy (Figs. 5 and $6, P>0.05)$. Of note, most of the patients ( $80 \%)$ who responded to BGD maintain their response for at least 6 months (Fig. 1). In a subgroup of 9 patients $\geq 60$ years old, $5(55.6 \%)$ patients achieved CMR, $2(22.2 \%)$-PMR (ORR 77.8\%), and 2 patients progressed during BGD treatment. PFS at 18 months was $62.2 \%$ (95\%CI: 35.5-100) and $\mathrm{OS}$ at 23 months was $87.5 \%$ (95\% CI: 67.3-100) (Figs. 7 and 8). 
Fig. 3 Progression-free survival (PFS) for the subjects with relapsed or primary refractory Hodgkin lymphoma (HL)

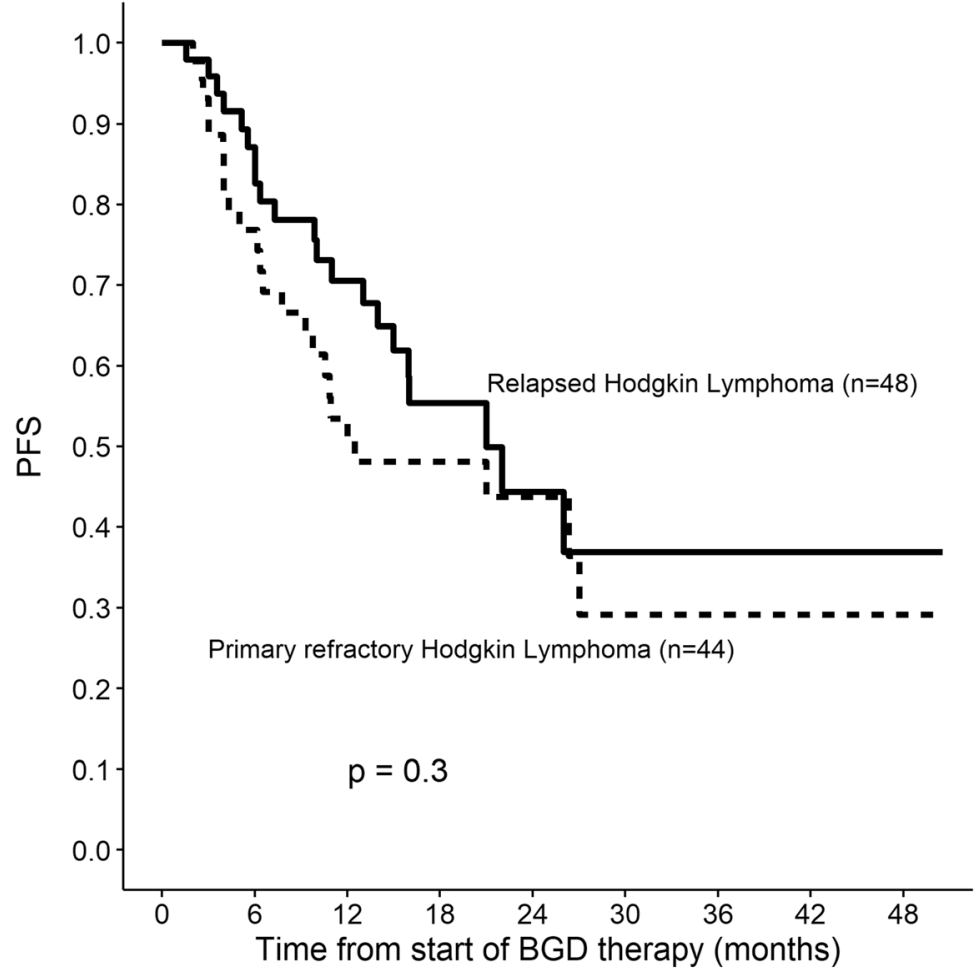

Number at risk

\begin{tabular}{|c|c|c|c|c|c|c|c|c|c|}
\hline Relapsed & 48 & 39 & 27 & 15 & 7 & 4 & 4 & 2 & 1 \\
\hline \multirow[t]{2}{*}{ Primary refractory } & 44 & 31 & 20 & 13 & 10 & 3 & 2 & 2 & 1 \\
\hline & 0 & 6 & $\begin{array}{l}12 \\
\text { fro }\end{array}$ & $\begin{array}{c}18 \\
\text { star }\end{array}$ & 24 & 30 & $\begin{array}{l}36 \\
y(n\end{array}$ & $\begin{array}{c}42 \\
\text { ths }\end{array}$ & 48 \\
\hline
\end{tabular}

\section{Toxicity of BGD}

The treatment-related AEs, mainly grade 1 or 2 , were observed in $64(69.6 \%)$ patients. Among grade $\geq 3$ hematological toxicities, anemia was reported in $15.2 \%$ cases, thrombocytopenia in $20.7 \%$, and neutropenia in $22.8 \%$ individuals. Severe non-hematological toxicities included infections $(10.9 \%)$, alanine and/or aspartate aminotransferase (ALT or AST) increase (2.2\%), and skin rush $(1.1 \%)$. We recorded one death from unknown reasons during BGD therapy. All AEs reported during BGD therapy are shown in Table 4. In the subgroup of elderly patients ( $\geq 60$ years), anemia and thrombocytopenia of grade 3 or 4 occurred in $2(22.2 \%)$ patients, while neutropenia was found in $1(11.1 \%)$ patient. Moreover, 2 $(22.2 \%)$ patients experienced grade $\geq 3$ infection, and 1 $(11.1 \%)$ grade 3 skin rash in this subgroup.

\section{Discussion}

Despite the significant progress in the management of patients with HL, relapsed and refractory disease constitutes a big challenge. According to the current treatment standards, high-dose chemotherapy followed by autoHCT has to be regarded as treatment of choice in the first relapse or primary progressive disease. However, even in the era of new agents such as brentuximab vedotin (BV) or immune checkpoint inhibitors, there are no accepted standards for salvage treatment before autoHCT. In the PLRG allied centers BGD was used since 2012 when the first cases of successful outcome of heavily pretreated patients were reported [16]. We had started to use BGD since both bendamustine and gemcitabine were effective in monotherapy as well as in combination with other agents. 
Fig. 4 Overall survival (OS) for the subjects with relapsed or primary refractory Hodgkin lymphoma (HL)

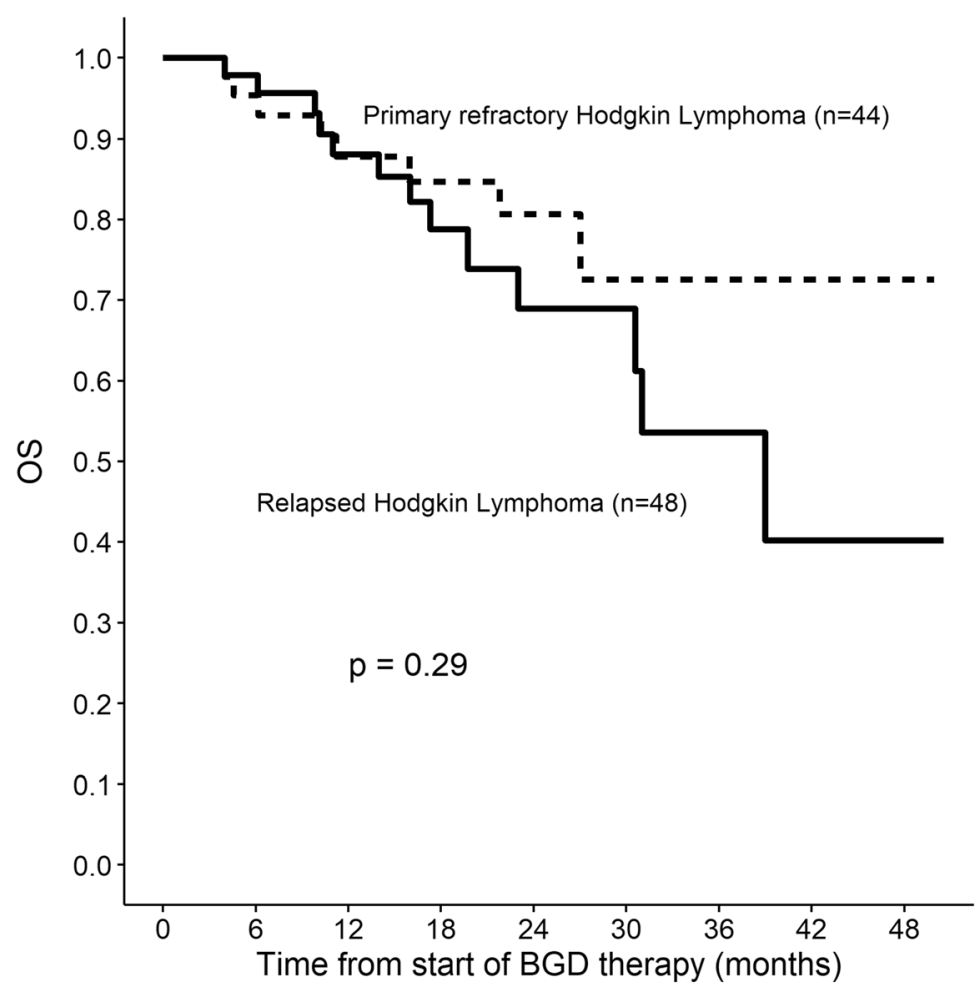

\section{Number at risk}

\begin{tabular}{|c|c|c|c|c|c|c|c|c|c|}
\hline Relapsed & 48 & 44 & 34 & 22 & 12 & 9 & 5 & 2 & 1 \\
\hline \multirow[t]{2}{*}{ Primary refractory } & 44 & 40 & 33 & 23 & 18 & 6 & 4 & 4 & 1 \\
\hline & 0 & 6 & 12 & 18 & 24 & 30 & 36 & 42 & 48 \\
\hline
\end{tabular}

Gemcitabine, a cytidine analog, was assessed in several studies. Kuruvilla et al. showed satisfactory $(62 \%)$ response rate to GDP (gemcitabine, dexamethasone, and cisplatin) as a second-line therapy in patients with $R / R$ HL [19]. Gemcitabine and vinerolbine combination showed ORR of $72 \%$ and $35 \%$ of CR [20]. In similar population, four-agent combination of gemcitabine with ifosfamide, vinorelbine, and prednisolone (IGEV) or double-agent schema of vinorelbine and pegylated liposomal doxorubicin (GVD) resulted in ORR of $81.3 \%$ and $70 \%$, respectively $[8,9]$. Bendamustine, another component of BGD, is a molecule containing the purine analog and the alkylating group. It was assessed in a phase II trial in heavily pretreated patients with HL (including those with relapse after auto- or alloHCT) at the dose of 120 $\mathrm{mg} / \mathrm{m}^{2}$ and resulted in the intent-to-treat ORR of $53 \%$, with CRs of $33 \%$ [11].
The combination of bendamustine with gemcitabine and vinorelbine (BeGEV) was first assessed in a multicenter phase II study by Santoro et al. [14]. The authors have demonstrated high efficacy of BeGEV as a second-line treatment in autoHCT-eligible patients (ORR 83\%, CR 75\%). In our retrospective analysis, ORR of BGD was similar to BeGEV although patient characteristics with regard to age and number of prior treatment regimens differ [14]. Moreover, almost onefourth of patients in our study had been treated using autoHCT. This also most likely explains slightly higher rate of hematological toxicities at grade 3 or 4 in comparison to BeGEV. In contrast, severe non-hematological AEs occurred at similar incidence rates. We did not observe increased pulmonary toxicity which was reported by Cohen et al. in his cohort of patients. This might be due to the use of high dose of steroids (dexamethasone) in our regimen [21]. However, in spite of high efficacy of BGD in relation 
Fig. 5 Progression-free survival (PFS) for patients treated with $\mathrm{BGD}$ as second or subsequent line of chemotherapy to ORR and CMR rate, estimated PFS in our study seems to be rather short (21 months). Most likely, this is a consequence of the large group of heavily pretreated patients (up to 6 previous line of therapy) including those after auto- and alloHCT and the subgroup of elderly patients in this cohort.

DHAP and ICE are among of the most commonly used salvage chemotherapy regimens in HL. Similar efficacy of these regimens as the second-line treatment was shown resulting in ORR of $88 \%$ for both, while CRs of $21 \%$ for DHAP and of $26.2 \%$ for ICE [5, 6]. Despite more heavily pretreated patients in our study, we report comparable ORR $(80.4 \%)$ and much higher CMR rate $(55.4 \%)$. Moreover, the difference in relation to $\mathrm{CR}$ rate increases in subanalysis restricted to patients treated with BGD as the second line of chemotherapy $(64.7 \%)$. The optimal number of
BGD cycles is four, since about $40 \%$ of patients improved their response at the end of treatment compared to the interim assessment.

Most patients $(80.4 \%)$ in this study were treated with ABVD as the first line of chemotherapy. Out of 13 patients being initially treated with BEACOPP, 5 (38.5\%) patients were refractory to this regimen and all these patients achieved ORR after BGD therapy with CMR rate of $40 \%$. In view of the fact that there are not many effective treatment options to overcome the BEACOPP refractoriness, this finding seems very interesting and encouraging for further studies.

In recent years, there have been many new agents evaluated for patients with $\mathrm{R} / \mathrm{R}$ HL such as $\mathrm{BV}$ and immune checkpoint inhibitors. Brentuximab vedotinan anti-CD30 antibody conjugated to antimicrotubule 
Fig. 6 Overall survival (OS) for patients treated with BGD as second or subsequent line of chemotherapy agent, monomethyl auristatin E-showed ORR of $75 \%$ and $\mathrm{CR}$ rate of $34 \%$ in heavily pretreated patients with HL after autoHCT [22]. Furthermore, BV showed similar efficacy as a second-line therapy in R/R HL (ORR $68 \%, \mathrm{CR} 35 \%$ ), and $89 \%$ of the subjects were able to proceed to autoHCT [23]. Addition of bendamustine to BV seems to increase its efficacy [12, 13]. However, in comparison to BGD regimen, BV does not appear to be superior both in monotherapy and in combination with bendamustine. Immune checkpoint inhibitors, mainly antibodies against programmed cell death protein 1 (PD-1) such as nivolumab or pembrolizumab, showed high efficacy as a salvage therapy for patients with $R / R$ HL [24-27]. Ansell et al. reported ORR $87 \%$ in the heavily pretreated HL patients although CR rate was relatively low (17\%) compared to BGD [24]. The authors reported similar incidence of AEs of any grade (78\% vs. 69.6\%) but relatively fewer cases of grade $\geq 3$ AEs (22\% vs. $38 \%$ ) during nivolumab therapy when compared to BGD therapy [24].

The high efficacy of BGD in patients after failure of autoHCT is worth noting. This is a very challenging group, in which effective chemotherapy followed by alloHCT is the only option to achieve long-lasting remission. In this population checkpoint inhibitors, nivolumab and pembrolizumab resulted in high ORR rate (69\% and $73 \%$, respectively). However, once again, CR rates (16\% and $14 \%$, respectively) appear lower compared to BGD in our study (55.4\%) and there are still some concerns about the increased incidence of immune complications after alloHCT in patients treated with immune checkpoint inhibitors before transplant $[25,26$, 28, 29]. 
Fig. 7 Progression-free survival (PFS) for the subgroup of elderly patients $(\geq 60$ years)

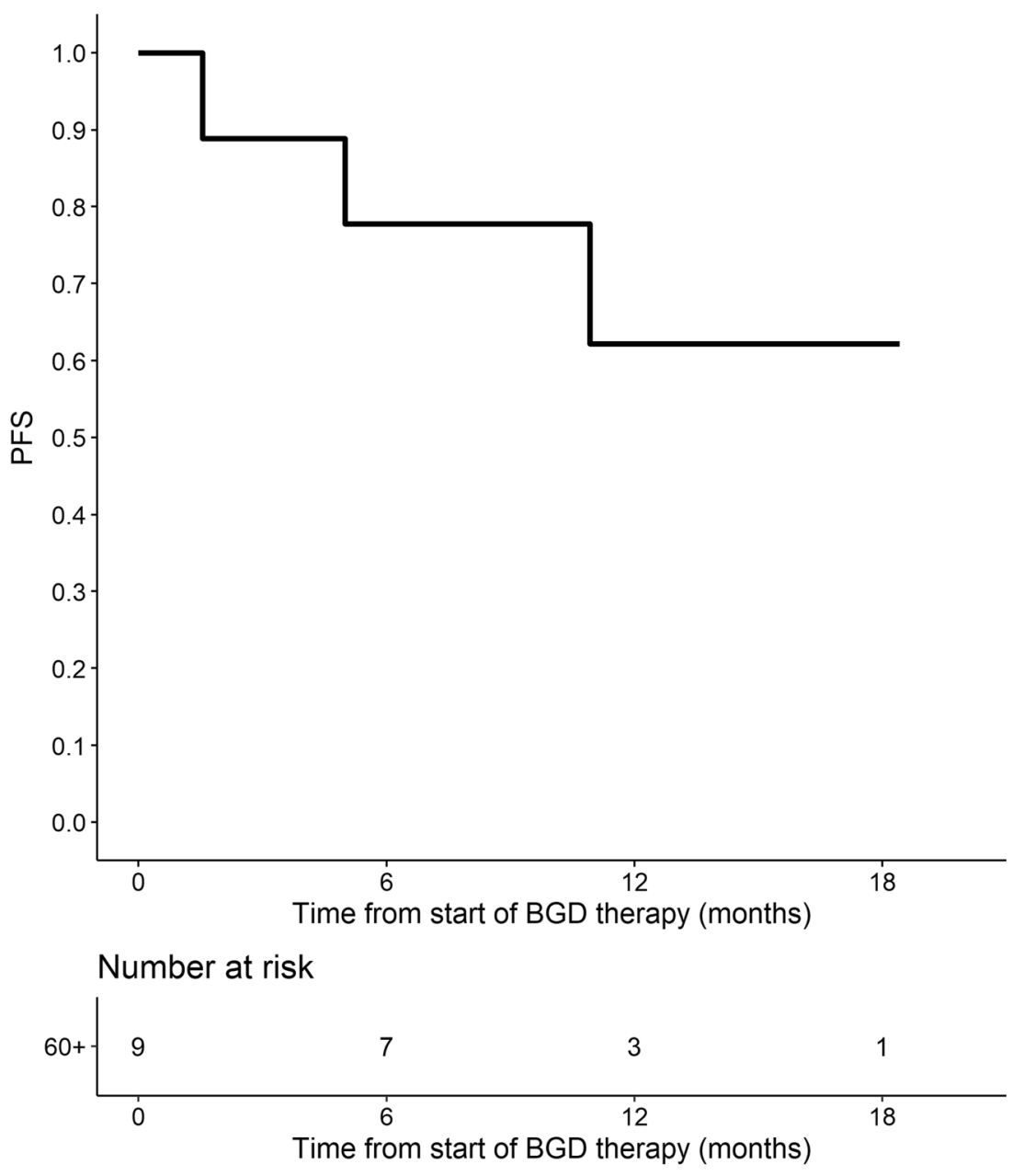

Another interesting finding of this study refers to elderly HL patients. We showed that in the patients at or above the age of 60 years BGD regimen has a similar efficacy (ORR $77.8 \%$, CMR 55.6\%) than in younger patients. Moreover, BGD-related toxicity seems to be acceptable in this subgroup.

Relatively small number of subjects included in the analysis as well as its retrospective nature and the lack of metabolic assessment in all patients are the major limitations of this study. Another important limitation of our study is a long accrual time. However, during this period, most of our patients were treated uniformly since novel therapies were not available due to reimbursement hurdles. Addition limitation may pose a large number of accruing centers. However, most of PLRG allied centers are reference centers with good-quality data management which somehow mitigate this flaw. However, our data clearly indicate that $\mathrm{BGD}$ which has a high rate of obtaining ORR and a relatively good time in response maintaining (5-6 months in $80 \%$ of patients) and an acceptable toxicity profile seems to provide a very good option for R/R HL patients even after BEACOPP firstline chemotherapy. In several patients, it opened a window to perform either autologous or allogeneic transplantation. Despite the fact that in recent years new treatment options, including BV and checkpoint inhibitors, showed promising results in treatment of patients with $\mathrm{R} / \mathrm{R} H \mathrm{H}$, neither of them as yet is formally approved in the secondline treatment for HL. In addition, although pharmacoeconomy was not a subject of this study, we speculate that BGD treatment may be a relatively cheap option. Therefore, we conclude that the BGD should be considered a viable option for patients with $\mathrm{R} / \mathrm{R}$ HL and may serve as a bridge for individuals being candidates for auto- or alloHCT. 
Fig. 8 Overall survival (OS) for the subgroup of elderly patients $(\geq$ 60 years)
Table 4 Toxicity of BGD therapy

\begin{tabular}{lll}
\hline Toxicity & $\begin{array}{l}\text { Grade 1-2 } \\
\text { No. (\%) }\end{array}$ & $\begin{array}{l}\text { Grade 3-4 } \\
\text { No. (\%) }\end{array}$ \\
\hline Hematological: & & \\
- Anemia & $37(40.2)$ & $14(15.2)$ \\
- Thrombocytopenia & $25(27.2)$ & $19(20.7)$ \\
- Neutropenia & $19(20.7)$ & $21(22.8)$ \\
Non-hematological: & & \\
- Infection & $20(21.7)$ & $10(10.9)$ \\
- ALT/AST increase & 0 & $2(2.2)$ \\
- Skin rush & $7(7.6)$ & $1(1.1)$ \\
- Fatigue & $4(4.3)$ & 0 \\
- Diarrhea & $1(1.1)$ & 0 \\
- Thrombotic events & $2(2.2)$ & 0 \\
- Guillain-Barré syndrome & $1(1.1)$ & 0 \\
- Autoimmune thyroiditis & $1(1.1)$ & 0 \\
Death from unknown reasons & & $1(1.1)$ \\
\hline
\end{tabular}

${ }^{\mathrm{a}}$ Alanine/aspartate aminotransferase

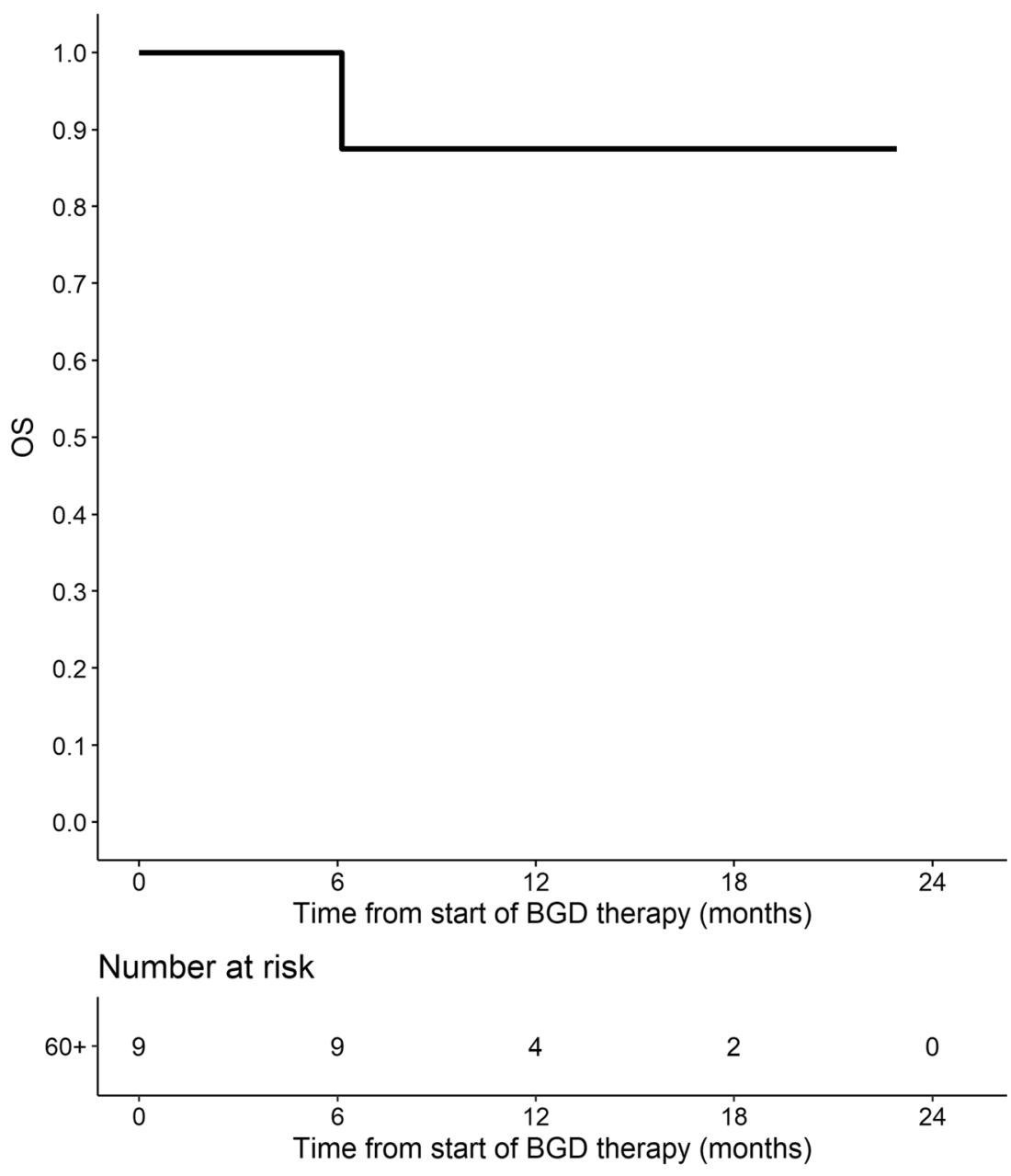

Author contributions WKP, JMZ, and SG designed the study; all authors except for JMZ, AK, and AW enrolled patients; SG, RS, AK, and AW performed the bioinformatics and statistical analysis; RS and JMZ wrote the paper. All authors read and revised the manuscript critically.

Data availability Not applicable

Code availability Not applicable

\section{Declarations}

Ethics approval According to Polish regulations, this was a retrospective study and it does not require approval of the bioethical committee. The study was approved by the board of The Polish Lymphoma Research Group.

Consent to participate Not applicable

Consent for publication Not applicable

Conflict of interest The authors declare no conflict of interest.

Open Access This article is licensed under a Creative Commons Attribution 4.0 International License, which permits use, sharing, 
adaptation, distribution and reproduction in any medium or format, as long as you give appropriate credit to the original author(s) and the source, provide a link to the Creative Commons licence, and indicate if changes were made. The images or other third party material in this article are included in the article's Creative Commons licence, unless indicated otherwise in a credit line to the material. If material is not included in the article's Creative Commons licence and your intended use is not permitted by statutory regulation or exceeds the permitted use, you will need to obtain permission directly from the copyright holder. To view a copy of this licence, visit http://creativecommons.org/licenses/by/4.0/.

\section{References}

1. Hoppe RT, Advani RH, Ai WZ, Ambinder RF, Aoun P, Armand P, Bello CM, Benitez CM, Bierman PJ, Chen R, Dabaja B, Dean R, Forero A, Gordon LI, Hernandez-Ilizaliturri FJ, Hochberg EP, Huang J, Johnston PB, Kaminski MS, Kenkre VP, Khan N, Maddocks K, Maloney DG, Metzger M, Moore JO, Morgan D, Moskowitz CH, Mulroney C, Rabinovitch R, Seropian S, Tao R, Winter JN, Yahalom J, Burns JL, Ogba N (2018) NCCN Guidelines Insights: Hodgkin lymphoma, Version 1.2018. J Natl Compr Canc Netw 16:245-254. https://doi.org/10.6004/jncen. 2018.0013

2. Schmitz N, Pfistner B, Sextro M, Sieber M, Carella AM, Haenel M, Boissevain F, Zschaber R, Müller P, Kirchner H, Lohri A, Decker S, Koch B, Hasenclever D, Goldstone AH, Diehl V, German Hodgkin's Lymphoma Study Group, Lymphoma Working Party of the European Group for Blood and Marrow Transplantation (2002) Aggressive conventional chemotherapy compared with high-dose chemotherapy with autologous haematopoietic stemcell transplantation for relapsed chemosensitive Hodgkin's disease: a randomised trial. Lancet 359:2065-2071. https://doi.org/10.1016/ S0140-6736(02)08938-9

3. Linch DC, Winfield D, Goldstone AH, Moir D, Hancock B, McMillan A, Chopra R, Milligan D, Hudson GV (1993) Dose intensification with autologous bone-marrow transplantation in relapsed and resistant Hodgkin's disease: results of a BNLI randomised trial. Lancet 341:1051-1054. https://doi.org/10.1016/ 0140-6736(93)92411-1

4. Moskowitz CH, Matasar MJ, Zelenetz AD, Nimer SD, Gerecitano J, Hamlin P, Horwitz S, Moskowitz AJ, Noy A, Palomba L, Perales MA, Portlock C, Straus D, Maragulia JC, Schoder H, Yahalom J (2012) Normalization of pre-ASCT, FDG-PET imaging with second-line, non-cross-resistant, chemotherapy programs improves event-free survival in patients with Hodgkin lymphoma. Blood 119:1665-1670. https://doi.org/10.1182/blood-2011-10-388058

5. Moskowitz CH, Nimer SD, Zelenetz AD, Trippett T, Hedrick EE, Filippa DA, Louie D, Gonzales M, Walits J, Coady-Lyons N, Qin J, Frank R, Bertino JR, Goy A, Noy A, O'Brien JP, Straus D, Portlock CS, Yahalom J (2001) A 2-step comprehensive high-dose chemoradiotherapy second-line program for relapsed and refractory Hodgkin disease: analysis by intent to treat and development of a prognostic model. Blood 97:616-623. https://doi.org/10.1182/ blood.v97.3.616

6. Josting A, Rudolph C, Reiser M, Mapara M, Sieber M, Kirchner HH, Dörken B, Hossfeld DK, Diehl V, Engert A, Participating Centers (2002) Time-intensified dexamethasone/cisplatin/ cytarabine: an effective salvage therapy with low toxicity in patients with relapsed and refractory Hodgkin's disease. Ann Oncol 13: 1628-1635. https://doi.org/10.1093/annonc/mdf221
7. Ramzi M, Rezvani A, Dehghani M (2015) GDP versus ESHAP Regimen in Relapsed and/or refractory Hodgkin lymphoma: a comparison study. Int J Hematol Oncol Stem Cell Res 9:10-14

8. Bartlett NL, Niedzwiecki D, Johnson JL, Friedberg JW, Johnson KB, van Besien K, Zelenetz AD, Cheson BD, Canellos GP, Cancer Leukemia Group B (2007) Gemcitabine, vinorelbine, and pegylated liposomal doxorubicin (GVD), a salvage regimen in relapsed Hodgkin's lymphoma: CALGB 59804. Ann Oncol 18:1071-1079

9. Santoro A, Magagnoli M, Spina M, Pinotti G, Siracusano L, Michieli M, Nozza A, Sarina B, Morenghi E, Castagna L, Tirelli U, Balzarotti M (2007) Ifosfamide, gemcitabine, and vinorelbine: a new induction regimen for refractory and relapsed Hodgkin's lymphoma. Haematologica 92:35-41

10. Gopal AK, Press OW, Shustov AR, Petersdorf SH, Gooley TA, Daniels JT, Garrison MA, Gjerset GF, Lonergan M, Murphy AE, Smith JC, Pagel JM (2010) Efficacy and safety of gemcitabine, carboplatin, dexamethasone, and rituximab in patients with relapsed/refractory lymphoma: a prospective multi-center phase II study by the Puget Sound Oncology Consortium. Leuk Lymphoma 51:1523-1529

11. Moskowitz AJ, Hamlin PA Jr, Perales MA, Gerecitano J, Horwitz SM, Matasar MJ, Noy A, Palomba ML, Portlock CS, Straus DJ, Graustein T, Zelenetz AD, Moskowitz CH (2013) Phase II study of bendamustine in relapsed and refractory Hodgkin lymphoma. J Clin Oncol 31:456-460. https://doi.org/10.1200/JCO.2012.45.3308

12. LaCasce AS, Bociek RG, Sawas A, Caimi P, Agura E, Matous J, Ansell SM, Crosswell HE, Islas-Ohlmayer M, Behler C, Cheung E, Forero-Torres A, Vose J, O'Connor OA, Josephson N, Wang Y, Advani R (2018) Brentuximab vedotin plus bendamustine: a highly active first salvage regimen for relapsed or refractory Hodgkin lymphoma. Blood 132:40-48. https://doi.org/10.1182/blood-2017-11815183

13. O'Connor OA, Lue JK, Sawas A, Amengual JE, Deng C, Kalac M, Falchi L, Marchi E, Turenne I, Lichtenstein R, Rojas C, Francescone M, Schwartz L, Cheng B, Savage KJ, Villa D, Crump M, Prica A, Kukreti V, Cremers S, Connors JM, Kuruvilla J (2018) Brentuximab vedotin plus bendamustine in relapsed or refractory Hodgkin's lymphoma: an international, multicentre, single-arm, phase 1-2 trial. Lancet Oncol 19:257-266. https://doi.org/ 10.1016/S1470-2045(17)30912-9

14. Santoro A, Mazza R, Pulsoni A, Re A, Bonfichi M, Zilioli VR, Salvi F, Merli F, Anastasia A, Luminari S, Annechini G, Gotti M, Peli A, Liberati AM, Di Renzo N, Castagna L, Giordano L, CarloStella C (2016) Bendamustine in combination with gemcitabine and vinorelbine is an effective regimen as induction chemotherapy before autologous stem-cell transplantation for relapsed or refractory Hodgkin lymphoma: final results of a multicenter phase ii study. J Clin Oncol 34:3293-3299. https://doi.org/10.1200/JCO.2016.66. 4466

15. Paszkiewicz-Kozik E, Zaucha J, Tyczyńska A, Szymanski M, Targonski L, Drozd-Sokolowska J, Wojciechowska-Lampka E, Tajer J, Kurczab P, Romejko-Jarosinska J, Osowiecki M, Walewski J (2017) Bendamustine, gemcitabine and dexamethasone chemotherapy is effective salvage and stem-cell mobilization regimen in patients with relapsed or refractory Hodgkin lymphomaearly results of the polish lymphoma research group study. Blood 130:4098

16. Knopińska-Posłuszny W, Kulikowski W, Paszkiewicz-Kozik E, Czyż A, Giza A, Chmielowska E, Drozd-Sokołowska J, Subocz E, Mendrek W, Spychałowicz W (2015) Zastosowanie bendamustyny z gemcytabiną i deksametazonem w leczeniu pierwotnie opornej i nawrotowej postaci chłoniaka Hodgkinawieloośrodkowe badanie obserwacyjne Polskiej Grupy Badawczej Chłoniaków (PLRG). Acta Haematol Pol 46:58-59

17. Cheson BD, Fisher RI, Barrington SF, Cavalli F, Schwartz LH, Zucca E, Lister TA, Alliance, Australasian Leukaemia and 
Lymphoma Group, Eastern Cooperative Oncology Group, European Mantle Cell Lymphoma Consortium, Italian Lymphoma Foundation, European Organisation for Research, Treatment of Cancer/Dutch Hemato-Oncology Group, Grupo Español de Médula Ósea, German High-Grade Lymphoma Study Group, German Hodgkin's Study Group, Japanese Lymphorra Study Group, Lymphoma Study Association, NCIC Clinical Trials Group, Nordic Lymphoma Study Group, Southwest Oncology Group; United Kingdom National Cancer Research Institute (2014) Recommendations for initial evaluation, staging, and response assessment of Hodgkin and non-Hodgkin lymphoma: the Lugano classification. J Clin Oncol 32:3059-3068

18. National Cancer Institute. Common Terminology Criteria for Adverse Events v4.0 (CTCAE). https://evs.nci.nih.gov/ftp1/ CTCAE/CTCAE 4.03/CTCAE 4.03 2010-06-14 QuickReference 5x7.pdf; Published: May 28, 2009

19. Kuruvilla J, Nagy T, Pintilie M, Tsang R, Keating A, Crump M (2006) Similar response rates and superior early progression-free survival with gemcitabine, dexamethasone, and cisplatin salvage therapy compared with carmustine, etoposide, cytarabine, and melphalan salvage therapy prior to autologous stem cell transplantation for recurrent or refractory Hodgkin lymphoma. Cancer 106:353360

20. Suyanı E, Sucak GT, Akı ȘZ, Yeğin ZA, Özkurt ZN, Yağcı M (2011) Gemcitabine and vinorelbine combination is effective in both as a salvage and mobilization regimen in relapsed or refractory Hodgkin lymphoma prior to ASCT. Ann Hematol 90:685-691. https://doi.org/10.1007/s00277-010-1113-Z

21. Cohen JB, Wei L, Maddocks KJ, Christian B, Heffner LT, Langston AA, Lechowicz MJ, Porcu P, Flowers CR, Devine SM, Blum KA (2020) Gemcitabine and bendamustine is a safe and effective salvage regimen for patients with recurrent/refractory Hodgkin lymphoma: results of a phase $1 / 2$ study. Cancer 126: 1235-1242

22. Younes A, Gopal AK, Smith SE, Ansell SM, Rosenblatt JD, Savage KJ, Ramchandren R, Bartlett NL, Cheson BD, de Vos S, Forero-Torres A, Moskowitz CH, Connors JM, Engert A, Larsen EK, Kennedy DA, Sievers EL, Chen R (2012) Results of a pivotal phase II study of brentuximab vedotin for patients with relapsed or refractory Hodgkin's lymphoma. J Clin Oncol 30:2183-2189

23. Chen R, Palmer JM, Martin P, Tsai N, Kim Y, Chen BT, Popplewell L, Siddiqi T, Thomas SH, Mott M, Sahebi F, Armenian S, Leonard J, Nademanee A, Forman SJ (2015) Results of a multicenter phase II trial of brentuximab vedotin as second-line therapy before autologous transplantation in relapsed/ refractory Hodgkin Lymphoma. Biol Blood Marrow Transplant 21:2136-2140

24. Ansell SM, Lesokhin AM, Borrello I, Halwani A, Scott EC, Gutierrez M, Schuster SJ, Millenson MM, Cattry D, Freeman GJ, Rodig SJ, Chapuy B, Ligon AH, Zhu L, Grosso JF, Kim SY, Timmerman JM, Shipp MA, Armand P (2015) PD-1 blockade with nivolumab in relapsed or refractory Hodgkin's lymphoma. N Engl J Med 372:311-319

25. Armand P, Engert A, Younes A, Fanale M, Santoro A, Zinzani PL, Timmerman JM, Collins GP, Ramchandren R, Cohen JB, De Boer JP, Kuruvilla J, Savage KJ, Trneny M, Shipp MA, Kato K, Sumbul A, Farsaci B, Ansell SM (2018) Nivolumab for relapsed/refractory classic Hodgkin lymphoma after failure of autologous hematopoietic cell transplantation: extended follow-up of the multicohort single-arm phase II CheckMate 205 Trial. J Clin Oncol 36:14281439

26. Armand P, Shipp MA, Ribrag V, Michot JM, Zinzani PL, Kuruvilla J, Snyder ES, Ricart AD, Balakumaran A, Rose S, Moskowitz CH (2016) Programmed death-1 blockade with pembrolizumab in patients with classical Hodgkin lymphoma after brentuximab vedotin failure. J Clin Oncol 34:3733-3739

27. Chen R, Zinzani PL, Fanale MA, Armand P, Johnson NA, Brice P, Radford J, Ribrag V, Molin D, Vassilakopoulos TP, Tomita A, von Tresckow B, Shipp MA, Zhang Y, Ricart AD, Balakumaran A, Moskowitz CH, KEYNOTE-087 (2017) Phase II study of the efficacy and safety of pembrolizumab for relapsed/refractory classic Hodgkin lymphoma. J Clin Oncol 35:2125-2132

28. Merryman RW, Kim HT, Zinzani PL, Carlo-Stella C, Ansell SM, Perales MA, Avigdor A, Halwani AS, Houot R, Marchand T, Dhedin N, Lescaut W, Thiebaut-Bertrand A, François S, Stamatoullas-Bastard A, Rohrlich PS, Labussière Wallet H, Castagna L, Santoro A, Bachanova V, Bresler SC, Srivastava A, Kim H, Pesek E, Chammas M, Reynolds C, Ho VT, Antin JH, Ritz J, Soiffer RJ, Armand P (2017) Safety and efficacy of allogeneic hematopoietic stem cell transplant after PD-1 blockade in relapsed/ refractory lymphoma. Blood 129:1380-1388 1182/blood-2016-09738385

29. Oshima Y, Tanimoto T, Yuji K, Tojo A (2017) Association between GvHD and nivolumab in the FDA adverse event reporting system. Bone Marrow Transplant 52:1463-1464. https://doi.org/ 10.1038/bmt.2017.158

Publisher's note Springer Nature remains neutral with regard to jurisdictional claims in published maps and institutional affiliations. 